\title{
Risk evaluation of domino effect of dam failures on small river-basins
}

\author{
Ivan Vaníček ${ }^{1, a}$, Jiř̌i Vaníček ${ }^{2}$ and Tomáš Pecival ${ }^{3}$ \\ ${ }^{1}$ Faculty of Civil Eng. CTU in Prague, Thákurova str. 7, 16629 Prague 6, Czech Republic \\ ${ }^{2}$ Geosyntetika Ltd., Nikoly Tesly str. 3, 16000 Prague 6, Czech Republic \\ ${ }^{3}$ VD TBD a.s. Hybernská str. 1617/40, 11000 Prague 1, Czech Republic
}

\begin{abstract}
Floods in 2002 pointed out on very sensitive problem of domino effect of small historical dam failures situated close to each other (in cascade), namely if the most significant dam is situated as the first one. The practical example of domino effect, which was observed during these floods, raised the attention to this type of failure. Firstly on the selection of river basins where the potential to the domino effect is very high and secondly on the detailed evaluation of the potential flood wave propagation below failed dam together with the impact of this wave on residential area and critical infrastructure. Therefore the paper focuses on detailed description of the practical case, on the evaluation of the limit state of failure, on the methods of dam reconstruction and finally on the evaluation of the domino effect of failure potential.
\end{abstract}

\section{Brief description of the problem}

Roughly, between 400 and 600 years ago many small earth dams were constructed mainly in the south part of the Czech Republic. They were used for fish production and flood protection. To our days roughly one third survived, which means about 25000 of these small historical dams. Most of them were removed and land was used for other agricultural purposes, part of them failed. During catastrophic floods in 2002 many of them had some problems, but less than $0.3 \%$ failed. However, most of these failures occurred in places with high concentration of dams situated close each other, showing on the domino effect of failure, [1]. For future improvement, the problem was observed in more details and some of the results are presented in this paper.

Typical place, where the concentration of failures was extremely high is the river basin on the small river Lomnice close to the city Blatna, Fig. 1. It is important to recall briefly the history of these dams during last period. In 1890 during floods all 7 dams completely failed. After that only one dam - Podhajsky - had some problem, and in 1990 part of the dam was improved with the application of at these days new method, jet grouting, going from the crest up to the bedrock. In fact, jet grouting with width around $0.6 \mathrm{~m}$ created additional central core sealing. During 2002 floods, again all dams were strongly affected. Five dams failed and two others were damaged. Detailed description was published for the first time in 2004 [1] and also in 2008 [2]. Nevertheless it is obvious that either in 1890 or in 2002 the domino effect of failures played there specific role. To decrease the potential of the failure in the future a great attention is now devoted to this specific problem not only for this small river basin but also for others with similar character from the view of cascade arrangement of these dams. Some experiences gained during last years are roughly summarized in this paper.
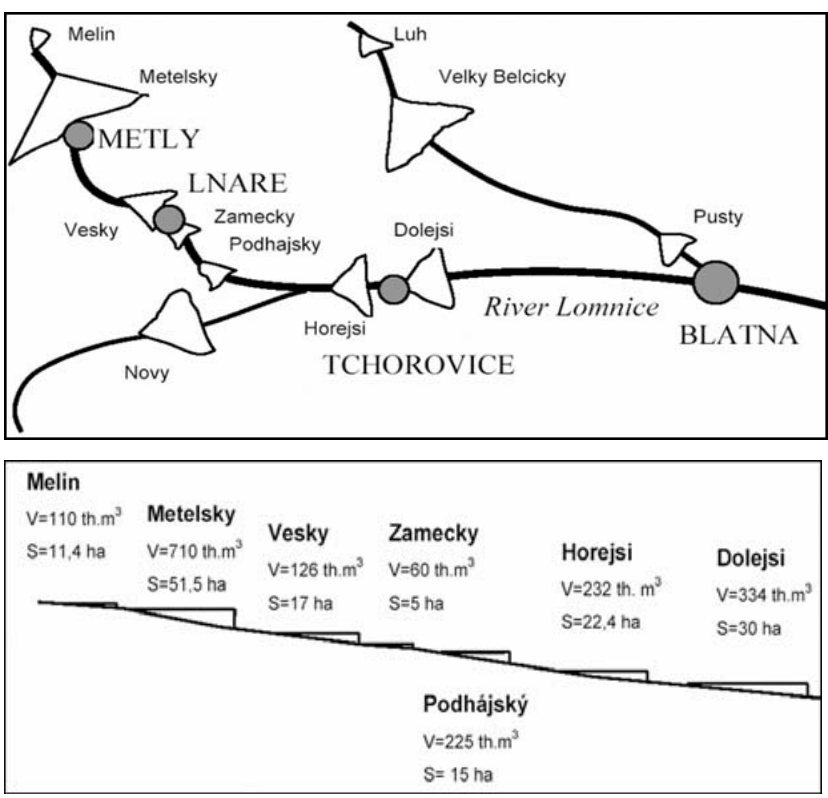

Figure 1. Situation and schematic cross section of small dams on River Lomnice $\left(1 \mathrm{ha}=10000 \mathrm{~m}^{2}\right.$, th. $=$ thousand $\left.=1.10^{3}\right)$

\section{Character of failures}

Historical dams at this area were constructed as homogeneous dams from the local material - granite eluvium. Observation approved that when floods reached roughly 100 years flood, all dams survived as the

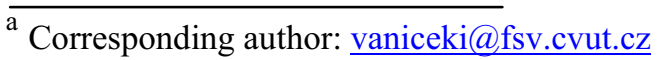


capacity of the bottom outlet and surface spillway were already checked for such flood. After that the first one, relatively small dam Melin, failed due to overflowing. When the additional flood wave from reservoir Melin reached the largest dam Metly, the erosion started there as well. In one place, the final erosion destroyed roughly half of the dam high showing on surface erosion. In the second place, the dam was eroded on all high and the main reason of failure was attributed to the internal erosion. Internal erosion with high probability started in the place were old wooden outlet was found, Fig. 2. From the historical records, this old outlet was left there roughly in seventeenth century, because from these days a new place for new outlet was selected.

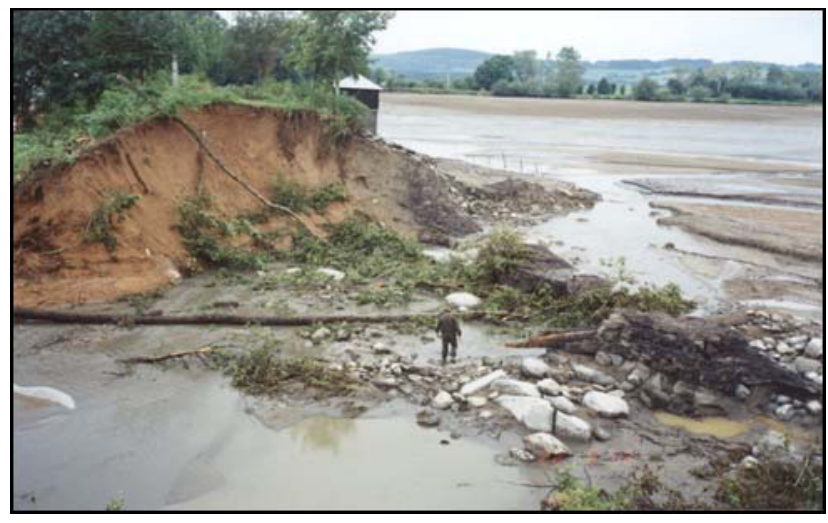

Figure 2. Dam Metelsky - breach caused by internal erosion

Relatively large volume from this reservoir (about $1 \mathrm{mil} . \mathrm{m}^{3}$ ), with the estimated (and recalculated) maximum outlet more than $500 \mathrm{~m}^{3} . \mathrm{s}^{-1}$ affected villages Metly and Predmir, where some houses were destroyed and one man died. The embankment of the next pond Vesky survived due to the very wide crest with asphalt pavement but was strongly eroded on the downstream side. The same situation was observed on the next pond Zamecky, the crest of which is also protected by asphalt pavement - the European road E 49 is passing through it.

The embankment of the fifth pond (Podhajsky) resisted to the additional wave for a few minutes, even when the water went over the crest. Finally also failed in the place where the reconstruction was realized in 1990. The reason of failure was attributed to the internal erosion, with high probability along the contact of the jet grouting sealing wall with bedrock, Fig. 3. Probably the internal erosion started as the result of the combination of higher hydraulic gradient and bad contact of the sealing wall with individual large granite boulders. Last two dams also failed completely as the result of surface erosion, Fig. 4. The wave after failure of the dam Horejsi strongly affected the village Tchorovice. After the failure of the last one (Dolejsi) the flood wave was getting flatter in much wider valley so that the impact on the town Blatna was diminished. However, even there the damages were very high, because on the brook, joining river Lomnice in Blatna, three dams (Luh, Velky Belcicky and Pusty) failed as well. The summary of the described case leads to the conclusion that after the failure of the largest dam Metelsky with largest reservoir at the beginning of this river basin, the dams below had small chance to survive, when additional unique flood wave reach them and this type of failure was described as domino effect, [1].

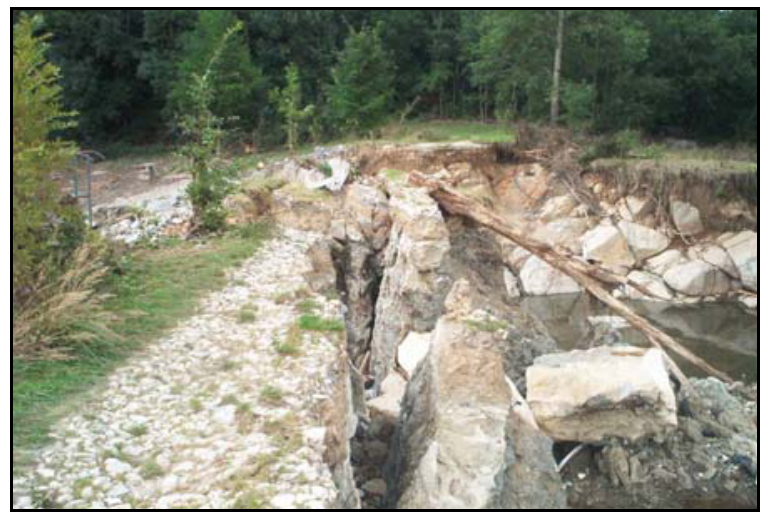

Figure 3. Dam Podhajsky. Failure by internal erosion along the contact of jet grouting sealing wall with boulders in bedrock

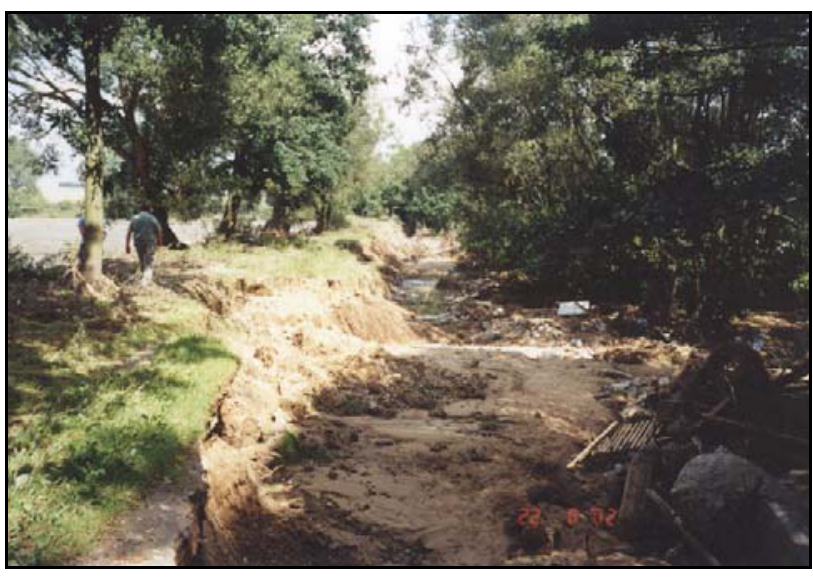

Figure 4. Dam Dolejsi. Typical character of surface erosion on the downstream slope

\section{Experiences gained during the dam reconstruction}

The reconstruction started very quickly after the failure. Two dams, which did not failed completely and crest of which is used as a main roadway, were reconstructed during 3 months. All others were reconstructed during the following 2 years.

First step of the reconstruction was connected with:

- Verification of hydrological conditions, recalculation of spillway capacity for 100 years outlet and supplemented increase of this capacity, where necessary;

- Unification of the crest vertical alignment in all length, because some differences up to $0.3 \mathrm{~m}$ were observed;

- Selection of the place where addition unprotected spillway was recommended.

Most important step was connected with specification of soil for the reconstruction. Tests on material used in Middle Ages showed that the character of this material is close to sand, with limited percentage of fine particles. In addition, plasticity index was very low, plasticity limit in some cases hardy detectable. However, the permeability was relatively good, in the order of $10^{-8} \mathrm{~m} . \mathrm{s}^{-1}$. The main 
reason for some cohesion and relatively lower permeability, than should be judged from the grain size distribution curve, is probably high content of mica. The surface of such compacted soil is very glossy, similar to clayey soil. Selected borrow pit showed different phase of weathering with depth and therefore the coarser material was selectively used for the downstream side, supplemented by toe drain. In longitudinal direction in the central part of the cross section the contact between old and new fill was done with the help cut-off, in the bottom as well. A great care was devoted to the connection of the old and new reconstructed parts respectively to the connection of the new part with subsoil. In both cases cut-off was applied. For the embankment of the pond Podhajsky, a special arrangement was recommended and applied in the part where in slope and in the bottom of the gash great granite boulders were disclosed. These boulders were coated with bentonite slurry and most plastic material was compacted there in small layers by smaller compaction tamp.

Under the time pressure, the crest of the additional spillway was protected by concrete. However, with time we tested two other possibilities. The first one applied horizontal reinforcing layers in embankment cross section. Instead of classical geosynthetic reinforcement, the layers from fibre concrete from construction demolition waste (old concrete and bricks) were used. Model test in the scale 1:1 proved very high surface erosion resistivity. The second possibility applied anti erosion geosynthetic matrasses on the surface of dam crest and downstream slope, connected to the surface by long nails and by grass roots. This possibility was applied on real dam and also during overflowing showed high erosion resistivity.

\section{Evaluation of the domino effect of failure potential}

\subsection{Desk study}

Desk study started very early, as another river basin with higher concentration of small dams was registered during 2002 floods. Desk study exploited water management maps in the scale 1: 50000 which are covering all country, Fig. 5. First step controlled the distance of individual dams and their reservoir volumes for river basin under review. During the second step, the volume of the upper reservoir was compared with maximum retention volume of the dam situated below together with its outlet capacity and expected character of the additional flood wave. This desk study approved that there are tens of such small river basins and situation should be taken very seriously. Our Water law classifies dams into different categories according to the risk, with which the dam failure is connected - what the impact of failure can be on human lives, build up area, environment generally. For small historical dams, it is usually $3^{\text {rd }}$ or $4^{\text {th }}$ category, when the $3^{\text {rd }}$ needs better care, higher demands on technical-security control. Therefore, the first important step of the desk study was connected with specification of critical dam, which can start domino effect and this dam was recommended for reclassification into higher $\left(3^{\text {rd }}\right)$ category. This recommendation was accepted by Ministry of agriculture, which is responsible for the Water law and other decrees for water management. The significance of such step was approved during years 2009 to 2014 , when other cases of domino effect of failure were observed during local floods on smaller river basins, [3]. However, before the final reclassification the closer specification of the unique flood wave character was recommended via numerical modelling.

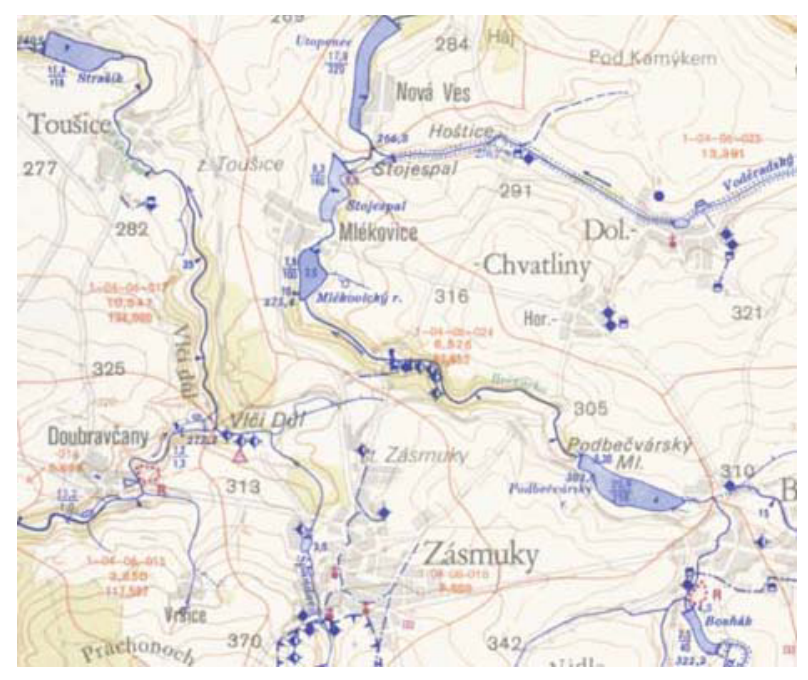

Figure 5. Illustrative concentration of small historical dams on water management map in the scale 1:50 000

\subsection{Modelling of flood wave propagation}

Study of the behaviour of the unique flood wave was performed for the valley of the river Brevnice, which was selected as prototypal example, as there are others operational dams (ponds), rest of historical dams, railway and motorway embankments and also few villages. Modelled area begins at the profile of the dam Brevnice and ends when river Brevnice flows into river Sazava. Total length is $15.5 \mathrm{~km}$.

Maximum high of the earth dam Brevnice is $12.5 \mathrm{~m}$, width of crest $3.5 \mathrm{~m}$, length of crest $230 \mathrm{~m}$, upstream slope 1:1.25-2, downstream slope 1:1.75-2.5. Storage capacity for storage level ( $526,10 \mathrm{~m}$ a.s.1.) is $504000 \mathrm{~m}^{3}$, for maximum level $\left(527.00 \mathrm{~m}\right.$ a.s.l.) $631000 \mathrm{~m}^{3}$ and for crest level (527.60 m a.s.1.) $730000 \mathrm{~m}^{3}$.

Digital model of the observed part of the valley was created with the help of basic maps in the scale 1:10 000 supported by geodetic survey. Selected cross sections were generated from this model.

The modelling is usually divided into two main phases. During the first one, the maximum outlet below failed dam is determined, supplemented by character of the flood wave. An overview of different models is presented e.g. in [4]. We used programme Boss Breach 2.0 (Nat. Weather Service, NOAA, Silver Spring, Maryland), which is modelling size and shape of breach together with outlet as the function of time and was sufficient for our purposes of study. The most dangerous 
scenario of dam breach counted with extreme flood wave $\left(Q_{1000}=19.0 \mathrm{~m}^{3} \cdot \mathrm{s}^{-1}\right)$. This value was derived from the analogy to the known value for $\mathrm{Q}_{100}$. Some results are as follows:

- 424 minutes from the beginning of simulation the dam crest overflowing starts; Unification of the crest vertical alignment in all length, because some differences up to $0.3 \mathrm{~m}$ were observed;

- Culmination of the outlet is reached after 453 minutes with maximum outlet $482 \mathrm{~m}^{3} \cdot \mathrm{s}^{-1}$,

- Total volume of outlet water for the phase of simulation is 0.9 mil. $\mathrm{m}^{3}$.

The result of this modelling is giving good image (and also starting point for the second phase of simulation) about maximum character of the break wave as the result of dam failure due to overflowing during extreme flood situation.

For the second phase the programme HEC-RAS (US ACE) was used, and special conditions were used for objects which should be in interaction with the modelled unique flood wave. HEC-RAS is in fact 1.5 D model, allowing For 3 existing dams the same manner of simulation was used as for the dam Brevnice. For 4 old breached functionless dams widening of breach was modelled as well. Modelling counted also with the capacity of outlet below bridges as well through culverts situated on transport infrastructures. The result of the numerical simulation is visible from the Fig. 6. Original peak of the break wave $482 \mathrm{~m} 3 . \mathrm{s}-1$ was decreased up to $112 \mathrm{~m}^{3} \cdot \mathrm{s}^{-1}$, what is the positive result with respect to the river Sazava, where the flow rate for 100 years hydrological flood wave is $154 \mathrm{~m}^{3} \cdot \mathrm{s}^{-1}$. Nevertheless modelling approved the failure of all 3 historical dams, together with first road embankment. However last railway embankment survived. With the help of simulation, it was possible also to define area, which will be flooded together with high of floodwater - information especially important for housing area.

Simulation model was consequently used for new scenarios, checking the sensitivity of some protective measures, which can be realized for existing dam, for old breached dams and for transport infrastructure. It is without any doubt that the increase of resistivity against surface erosion for existing dams is not only positive step for the decrease of failure probability but also for flood wave flattening. Simulation also showed that for old breached dams the best way is their reconstruction, and future utilization as dry dam, when the storage capacity of the reservoir can be fully used for wave flattening.

The interaction with transport infrastructure will be discussed in more details in next chapter.

\subsection{Interaction of flood with transport infrastructure}

The problem of interaction of transport infrastructure with natural hazards, like floods, is very sensitive all over the word. Flooding of the part of metro in Prague complicated city transport for few months. In addition, most of historical bridges had some problems in former times as the footing bottom was situated in shallow depths. Typical examples for the Czech Republic are stone bridges as Charles Bridge in Prague or bridge in town Pisek - both from the $14^{\text {th }}$ century. However, at the present time this problem was solved, protection of individual piers against erosion (scouring) was improved.

With respect to the discussed problem on small river basins, the most sensitive situation is connected with direct interaction of floods with transport infrastructure like railway and motorway embankments. For the described case on small river Lomnice it was documented, that asphalt pavement on the crest for two

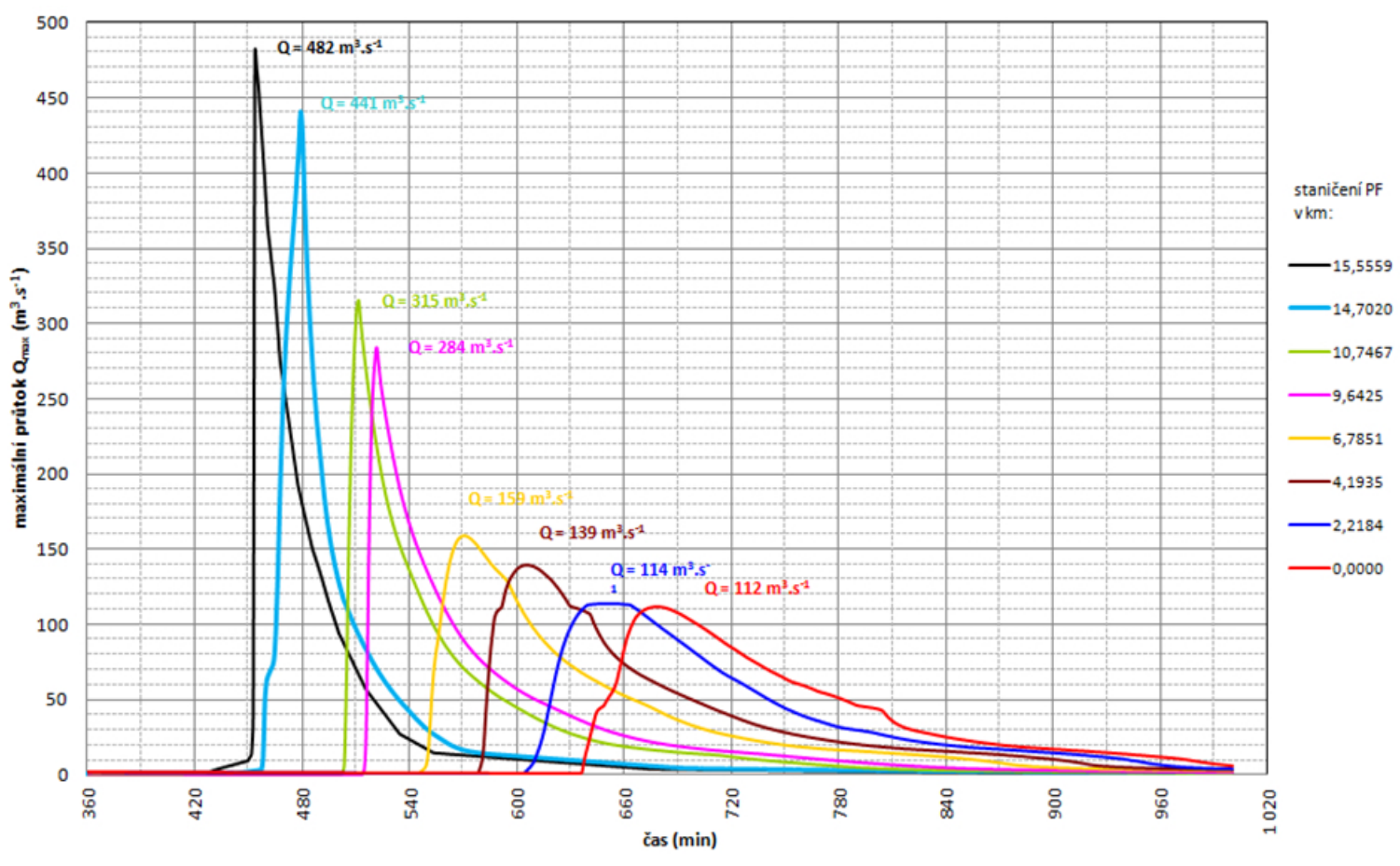

Figure 6. Progression of the flood wave culmination $\left(\mathrm{m}^{3} \cdot \mathrm{s}^{-1}\right)$ as function of time (min) for observed profiles 
motorways passing on the dam surface significantly improved surface resistivity. Dams were affected by surface erosion, Fig. 7, mostly on the downstream slope, but did not failed completely as during floods in 1890 . During desk study, similar case for railway track situated on the dam crest was found.

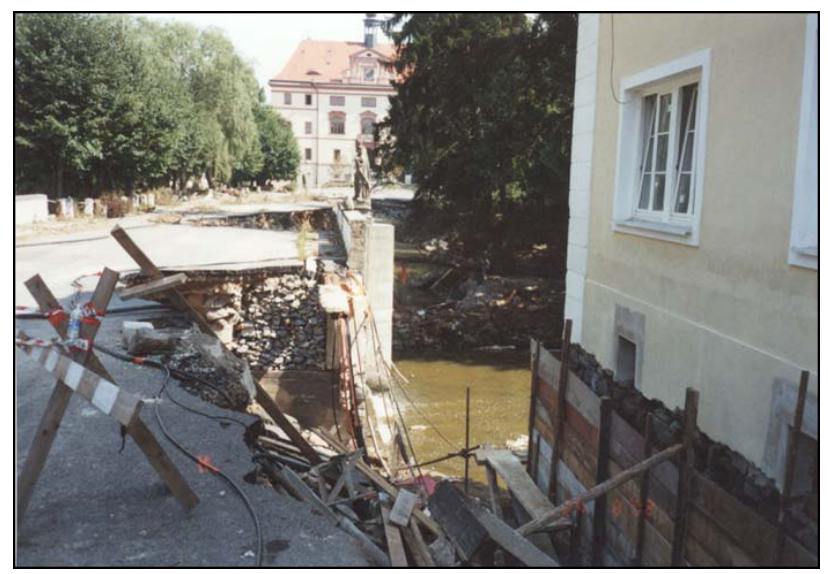

Figure 7. Dam Zamecky. Character of failure of the crest with asphalt pavement due to overflowing - E49 road

Special case is the interaction of transport embankment with flood wave. Railway track passing small river Lomnice below the dam Podhajsky was completely disturbed, Fig. 8. Outlet capacity of the flow profile was lower than flood wave and overflowing caused surface erosion leading to the total failure. Similar case was registered during numerical modelling for small river Brevnice. Road embankment situated below breached dam failed as outlet at this profile was still very high. Numerical modelling however also pointed out on the railway embankment, which survived as peak of the flood wave was much slower there. In this case, the positive impact on the flood wave flattening was much more significant.

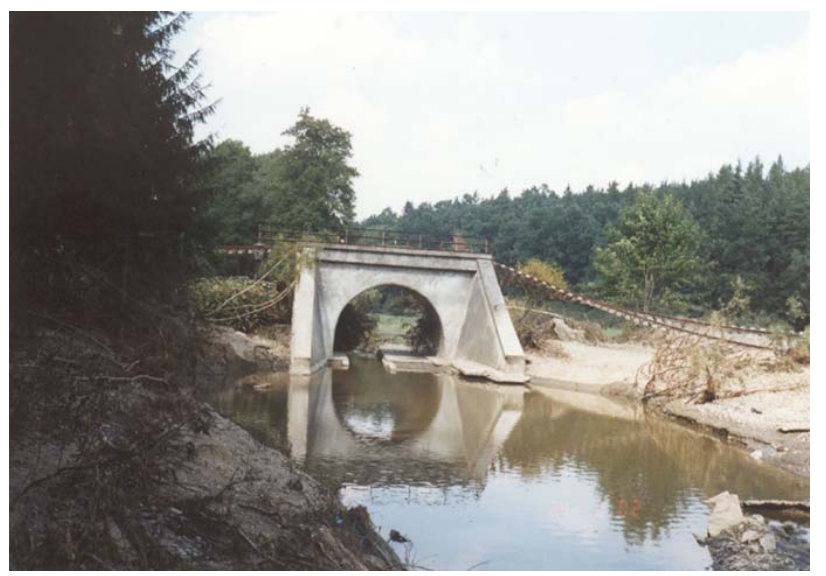

Figure 8. Failure of the railway embankment situated below the dam Podhajsky

Therefore, we can conclude that the transport infrastructures are playing significant role for the elimination of the domino effect of failure and our recommendation follows up the opportunity for increase resistivity, especially on the downstream slope of the transport embankment. Some methods described for downstream slope of dams in chapter 3 can be recommended also in this case.

\section{Conclusion}

The described case of the river basin of the small river Lomnice, where series of failures were observed, led to the conclusion that the domino effect of failure needs more attention especially from the view of extremely high concentration of small historical dams in the Czech Republic. Old files confirmed that such type of failure occurred also in previous years.

From the first point of this investigation, it was approved that the ultimate limit state of the type HYD is playing most important role, primary surface erosion, followed by internal erosion. Field observation demonstrated very positive impact of the asphalt pavement of the dam (dyke) crest. Large laboratory and field models approved the positive role of the dam reinforcement (with horizontal reinforcing layers) and also with anti-erosion matrasses very well connected to the dam crest and to the down-stream face, especially when this reinforcement was situated in the place of preferential crest overflowing.

During the reconstruction a great care should be devoted to the selection of the appropriate material for the reconstructed part. In our case, roughly the same material, as was used in Middle Ages was applied, even from the first view (grain size distribution) this soil was on the boundary which is now recommended. Special attention was focussed on the connection of the new part and old one, respectively connection of new part with subgrade. Additional spillway was recommended in the place where overflowing can be less dangerous and in this part, the crest of this spillway or all embankment is reinforced to be more resistible to the surface erosion. Practical application in the scale $1: 1$ approved this recommendation.

Not only observed practical example for the river Lomnice basin showed high sensitivity to the domino effect of failure, but also desk study of the water management maps showed that there exist very similar situation on large numbers of similar river basins. However, the final decision, what care should be devoted to these river basins, is recommended to control with the help of numerical modelling. Either with the help of modelling of the maximum peak of the unique flood wave leaving breached dam, but also with the help of numerical modelling of the unique flood wave spreading bellow this dam. Modelling is very useful tool for the specification of the potential risk of this unique flood, specifying the area, which can be flooded together with risk to the existing buildings and critical infrastructure. Specific attention was devoted to the interaction of this unique flood with transport infrastructure. The embankments of roads and railways can play positive role (wave flattening) up to the certain limit, but the possibility of the embankment overflowing have to be controlled as can lead to the transport infrastructure failure. 


\section{Acknowledgement}

The paper was prepared with the financial support of the research project TE0 120168 of the Technology Agency of the Czech Republic "CESTI" - Centrum of the effective and sustainable transport infrastructure.

\section{References}

1. Vaníček I. and Vaníček J. (2004). Rehabilitation of old earth dams failed during heavy flood in 2002. Proc. New Development in Dam Engineering. Balkema. 889-898

2. Vaníček I. and Vaníček M. (2008). Earth Structures in Transport, Water and Environmental Engineering. Springer Science+ Business Media B.V.. 637 p.

3. Pecival T. (2015). Research of frequency and types of failures for small earth dams - domino effect. $P h D$ thesis. (in Czech). Czech Technical University in Prague. 119 p.

4. Wahl T.L. (2010). Dam breach modelling - an overview of analysis methods. In: Proc. Joint Federal Interagency Conf. on Sedimentation and Hydrologic modelling. Las Vegas. 